PATHOPHYSIOLOGY OF PLASMA PROTEIN

METABOLISM 
To my wife Laura and my daughter Anna Giuliana 


\section{PATHOPHYSIOLOGY OF PLASMA PROTEIN METABOLISM}

Edited by

\section{GIULIANO MARIANI}

CNR Institute of Clinical Physiology, and Fifth Medical Pathology of the University of Pisa, Pisa, Italy

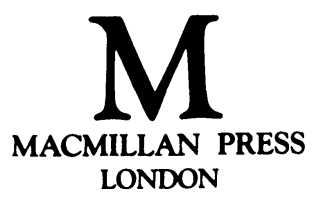


(C) The contributors 1984

Softcover reprint of the hardcover 1st edition 1984 978-0-333-34739-3

All rights reserved. No part of this publication may be reproduced or transmitted, in any form or by any means, without permission

First published 1984 by

The Scientific and Medical Division

THE MACMILLAN PRESS LTD

London and Basingstoke

Companies and representatives throughout the world

ISBN 978-1-349-06682-7

ISBN 978-1-349-06680-3 (eBook)

DOI 10.1007/978-1-349-06680-3

Typeset by

RDL Artset Ltd, Sutton, Surrey 


\section{Contents}

The contributors vii

Preface xi

Obituary to Mones Berman xii

Acknowledgements xiv

1 Large Models in the Study of Protein Metabolism

L. Zech and M. Berman 1

2 Optimal Experiment Design in Plasma Protein Metabolic Studies: Sequential Optimal Sampling Schedules for Quantifying Kinetics J. J. DiStefano, III

3 Formulation, Identification and Validation of Mathematical Models for Plasma Protein Metabolic Studies

D. G. Cramp, E. R. Carson and C. Cobelli

4 Kinetic Modelling for Distribution and Removal of Plasma Proteins with Altered Biological Behaviour in vivo

F. Vitek, G. Mariani and R. Bianchi

5 Regulation of the Interstitial Distribution of Plasma Proteins

V. M. Rosenoer and E. B. Reeve

6 In vivo and in vitro Regulation of Albumin Synthesis

M. A. Rothschild, M. Oratz and S. S. Schreiber

7 In vitro and in vivo Regulation of Immunoglobulin Synthesis

T. A. Waldmann

8 IgA Immunoglobulin Synthesis, Catabolism and Transport

W. Strober and H. Kawanishi

9 Regulation of Retained and Secreted Liver Proteins

H. Glaumann 
10 Metabolism of Radiolabelled Complement Proteins in Health and Disease

C. A. Alper and F. S. Rosen

11 Metabolic Studies of Acute-phase Proteins

$$
\text { A. Koj }
$$

12 Significance of in vivo and in vitro Metabolic Studies of Tumourproduced Proteins

G. Mariani, P. W. Sullivan, E. A. McGuire, K. R. McIntire, R. H. Adamson and T. A. Waldmann

13 Fibrinogen and Fibrinogen-related Peptides in Cancer

J. J. Franks, R. E. Kirsch, B. Kao and T. M. Kloppel

14 Studies of Antithrombin Turnover

E. B. Reeve, R. D. Bies, B. D. Leonard and A. Stephens

15 Nutritional Aspects of Plasma Protein Metabolic Studies:

Protein-Energy Malnutrition

P. G. Lunn

16 Nutritional Aspects of Plasma Protein Metabolic Studies: Long-term Treatment of Chronic Uraemia by a Very-low-protein Diet Supplemented with Essential Amino Acids and Keto Analogues

G. Mariani, G. Barsotti, S. Giovannetti and R. Bianchi

17 Kinetics of Apolipoproteins A-I and A-II
L. A. Zech, E. J. Schaefer, J. C. Osborne, Jr., R. L. Aamodt and

H. B. Brewer, Jr.

18 The Plasma Apolipoproteins: Physiological Properties and Possible Role in Lipid Disorders and Atherogenesis

G. Baggio, E. Manzato, R. Fellin and G. Crepaldi

19 Role of Cell-Surface Receptors in the Behaviour in vivo of

Transferrin

E. Regoeczi

Index 


\section{The contributors}

R. L. Aamodt

Department of Nuclear Medicine

The Clinical Center

National Institutes of Health

Bethesda

Maryland 20205

USA

R. H. Adamson

National Cancer Institute

National Institutes of Health

Bethesda

Maryland 20205

USA

Chester A. Alper

Center for Blood Research

and

Department of Medicine

Children's Hospital Medical Center

Boston

Massachusetts 02115

USA

Giovannella Baggio

Institute of Internal Medicine

Medical Pathology

University of Padua

35100 Padova

Italy

Giuliano Barsotti

First Medical Clinic of the University of Pisa

56100 Pisa

Italy

Mones Berman

Formerly Laboratory of Mathematical Biology

Division of Cancer Biology and Diagnosis

National Cancer Institute

National Institutes of Health

Bethesda
Maryland 20205

USA

R. Bianchi

Fifth Medical Pathology of the University of Pisa and C.N.R. Institute of Clinical Physiology 56100 Pisa

Italy

R. D. Bies

Clinical Research Center

University of Colorado

Denver

Colorado 80262

USA

H. B. Brewer, Jr.

Molecular Disease Branch

National Heart, Lung and Blood Institute

National Institutes of Health

Bethesda

Maryland 20205

USA

Ewart R. Carson

Department of Systems Science

The City University

London EC1V 0HB

UK

and

Department of Chemical Pathology

Royal Free Hospital School of Medicine

London NW3 2QG

UK

C. Cobelli

Instituto di Elettrotecnica e di Elettronica

Università di Padova

Italy

and

Laboratorio per Ricerche di Dinamica dei Sistemi e di Bioingegneria 
Consiglio Nazionale delle Ricerche 35100 Padova

Italy

D. G. Cramp

Department of Chemical Pathology

Royal Free Hospital School of Medicine

London NW3 2QG

UK

and

Department of Systems Science

The City University

London EC1V OHB

UK

G. Crepaldi

Institute of Internal Medicine

Medical Pathology

University of Padua

35100 Padova

Italy

Joseph J. DiStefano, III

Engineering Systems Department

School of Engineering and Applied Sciences

University of California

Los Angeles

California 90024

USA

R. Fellin

Institute of Internal Medicine

Medical Pathology

University of Padua

35100 Padova

Italy

John J. Franks

Hematology Section

Veterans Administration Center

Denver

Colorado 80220

USA

Sergio Giovannetti

First Medical Clinic of the University of

Pisa

56100 Pisa

Italy

Hans Glaumann

Department of Pathology

Karolinska Institute

Huddinge University Hospital

S-141 86 Huddinge

Sweden
Betty Kao

Hematology Section

Veterans Administration Center

Denver

Colorado 80220

USA

Hidenori Kawanishi

Mucosal Immunity Section

Laboratory of Clinical Investigation

National Institute of Allergy and Infectious Disease

National Institutes of Health

Bethesda

Maryland 20205

USA

Ralph E. Kirsch

Department of Medicine

Medical School

University of Cape Town

7900 Cape

Republic of South Africa

Thomas M. Kloppel

Hematology Section

Veterans Administration Medical Center

Denver

Colorado 80220

USA

Alex Koj

Institute of Molecular Biology

Jagellonian University

3-120 Krakow

Poland

B. D. Leonard

Clinical Research Center

University of Colorado

Denver

Colorado 80262

USA

Peter G. Lunn

M. R. C. Dunn Nutritional Laboratory

Cambridge

CB4 1XJ

UK

E. A. McGuire

Formerly National Cancer Institute

National Institutes of Health

Bethesda

Maryland 20205

USA (and see p. ix) 


\section{Present address:}

545 Anderson Avenue

Rockville

Maryland 20850

USA

\section{K. R. McIntire}

National Cancer Institute

National Institutes of Health

Bethesda

Maryland 20205

USA

Present address:

15 Main Street

Falmouth

Massachusetts 02540

USA

E. Manzato

Institute of Internal Medicine

Medical Pathology

University of Padua

35100 Padova

Italy

Giuliano Mariani

C.N.R. Institute of Clinical Physiology and Fifth Medical Pathology of the University of Pisa

56100 Pisa

Italy

M. Oratz

Department of Medicine

New York University Medical Center

New York

New York 10016

USA

J. C. Osborne, Jr.

Molecular Disease Branch

National Heart, Lung and Blood Institute

National Institutes of Health

Bethesda

Maryland 20205

USA

E. Basil Reeve

Clinical Research Center

University of Colorado

Denver

Colorado 80262

USA

Erwin Regoeczi

Department of Pathology

McMaster University Medical Centre

Hamilton
Ontario L8N $3 Z 5$

Canada

Fred S. Rosen

Department of Pediatrics

Harvard Medical School

Boston

Massachusetts

USA

Victor M. Rosenoer

Department of Medicine

School of Medicine

University of California

San Francisco

California 94143

USA

Marcus A. Rothschild

Nuclear Medicine Service

Veterans Administration Medical Center

New York

New York 10010

USA

E. J. Schaefer

Molecular Disease Branch

National Heart, Lung and Blood Institute

National Institutes of Health

Bethesda

Maryland 20205

USA

S. S. Schreiber

Department of Biochemistry

New York University Medical Center

New York

New York 10010

USA

A. Stephens

Clinical Research Center

University of Colorado

Denver

Colorado 80262

USA

Warren Strober

Mucosal Immunity Section

Laboratory of Clinical Investigation

National Institute of Allergy and Infectious Disease

National Institutes of Health

Bethesda

Maryland 20205

USA 
P. W. Sullivan

Formerly National Cancer Institute

National Institutes of Health

Bethesda

Maryland 20205

USA

Present address:

Children's Hospital of San Francisco

San Francisco

California 94119

USA

F. Vitek

Institute of Biophysics

Faculty of General Medicine

Charles University

Prague

Czechoslovakia
Thomas A. Waldmann

Metabolism Branch

National Cancer Institute

National Institutes of Health

Bethesda

Maryland 20205

USA

Loren Zech

Molecular Diseases Branch

Division of Intramural Research

National Heart, Lung and Blood Institute

National Institutes of Health

Bethesda

Maryland 20205

USA 


\section{Preface}

This book represents a factual account of the proceedings of an international symposium on the pathophysiology of plasma protein metabolism, which was organised in October 1982 by the Plasmaprotein and Immunology Division of the C.N.R. Institute of Clinical Physiology at the University of Pisa (Italy). Several of the contributors are former members of the International Study Group on Plasma Protein Metabolism, the last meeting of which was held in Turin (Italy) in 1974, under the auspices of the scientific organisation of the same institute.

The symposium took the form of a series of lectures, with the main objective of providing a positive contribution to the state of the art of several topics related to the kinetic and pathophysiological factors regulating the synthesis, distribution and degradation of plasma proteins.

The first four chapters form a group, each one considering a special aspect of the kinetics of turnover and distribution of plasma proteins in general; particular attention is paid to the recent advances in the field of kinetic modelling, the choice of the best models and the optimisation of the experimental designs. The next seven chapters consider the regulation of synthesis, distribution and catabolism of various classes of plasma proteins including albumin, immunoglobulins, complement fractions and acute-phase proteins. The remaining chapters deal with metabolic studies of various plasma proteins (including tumour markers, coagulation proteins and lipoproteins) in different disease states, such as malignancies, coagulative disorders, malnutrition and the extensive group of atherosclerotic cardiovascular diseases.

As editor, I would like to express my appreciation to the leading investigators in the field of protein metabolism who contributed chapters to this book.

Finally, I wish to express my deep gratitude to the two men who have greatly contributed to my scientific evolution. Professor Luigi Donato provided a unique broad perspective and overview coupled with a rational approach to biomedical research in general, and particularly to the pathophysiological view of the biological events which we have been studying. Professor Romano Bianchi's humanity, patient, encouragement, and stimulating and constructive criticisms throughout the years that I have known him have deeply influenced by own life, both professional and private. Without him this book would never have been published. 


\title{
Obituary
}

\author{
to \\ MONES BERMAN, 1920-1982
}

With Mones Berman's death on 12 August 1982 the world of modelling, mathematical biology and physics, including friends and students, lost an inspiring colleague and a spirit of unbounding energy and interest.

Born 20 August 1920 in Lithuania, he migrated to the United States in 1938. After serving in the Army Signal Corps, he received his bachelor's degree in electrical engineering from Cooper Union School of Engineering in 1950. He was with Sloan-Kettering Institute from 1946 to 1958, first as a researcher in isotope and radiation physics (1946-1948), then as an electronics engineer and fellow in charge of electronic instrumentation (1948-1953) and then as a biophysicist (1953-1958). Also, from 1953 to 1958 Dr Berman was an Assistant Professor of Biophysics at the Sloan-Kettering Division of Cornell Medical College. The summers of 1952 until 1958 were spent as the Chief Radiation Physicist of the Radiation and Isotope Laboratory, Woods Hole, Massachusetts.

In 1957 Mones received his doctorate in physics and a year later became a senior physicist of the Mathematical Research Branch, National Institute of Arthritis and Metabolic Diseases, where he continued to apply his broad background in physics to the basic understanding of biological problems. In 1972 he was appointed acting chief of the Laboratory of Theoretical Biology, National Cancer Institute, where he remained until 1981, when he became chief of the renamed Laboratory of Mathematical Biology.

His international reputation stems from the world-wide use of the SAAM (Simulation, Analysis And Modelling) computer program package and the application of his modelling methodology and mathematical techniques to the study of biological systems. He investigated the kinetics of pharmaceuticals, lipids, lipoproteins, amino acids, glucose, insulin, calcium, zinc, lithium and many other systems. These endeavours led Mones to be actively involved in more than a dozen consultancies and committees, including the Editorial Board of The Journal of Lipid Research and the American Journal of Physiology. 
All who knew Mones Berman realise that a listing of his scientific, teaching and organisational activities leaves untouched the essence of his recognition as an unusual human being. His global view of life was a constant source of inspiration, encouraging those who interacted with him to become pupils of this view. 


\section{Acknowledgements}

The organisation of the international symposium on the pathophysiology of plasma protein metabolism, which took place in October 1982, and the subsequent publication of this book would not have been possible without the generous financial contribution of the Italian Association for the Study and Production of Human Blood Derivatives (A.S.P.E., Rome, Italy).

This scientific initiative was also supported by a P.H.S. Grant (No. CA34821) awarded by the National Cancer Institute of the National Institutes of Health, Department of Health and Human Services (USA), and by two grants from the Italian National Research Council. 